\title{
Evaluation of Corneal Endothelial Changes Using Specular Microscope before and after Collagen Cross Linking for the Treatment of Keratoconus
}

\author{
NEGM E. HELAL, M.D.; LAMIAA S. ELEWA, M.D.; KHALED M. HAMDY, M.D. and \\ RANA S. MOHAMED, M.Sc.
}

The Department of Ophthalmology, Faculty of Medicine, Ain Shams University

\begin{abstract}
Background: Keratoconus is a non-inflammatory condition in which the center of the cornea progressively thins and develops a cone-shaped bulge that blurs and distorts vision. A normal cornea is round, with even curvature like that of a sphere. But with keratoconus, the curvature is irregular and too steep, like the narrow end of an egg. Any change in the shape of the cornea changes the way light passes through the eye, and results in a change in vision. When the cornea is too steep, light converges in front of the retina, causing nearsightedness.
\end{abstract}

Aim of the Work: The purpose of this work is to evaluate the corneal endothelial changes following corneal collagen cross linking (CXL) for the treatment of progressive keratoconus using corneal specular microscopy.

Patient and Methods: This study was a prospective, nonrandomised controlled interventional case series. Patients from age 18 to 40 years old diagnosed with progressive keratoconus tested to detect if there is change in corneal endothelium after cross linking or not.

Results: Our study was done on 40 eyes in patient age from 18-40 years old. It showed that there were statistically non significant changes in corneal endothelial counts include central corneal thickness (CCT), endothelial cell density (ECD), coefficient of variation (CV\%), Hexagonal cells \%, after cross linking procedure in keratoconic patients during one month follow-up.

Conclusion: Our results demonstrated no changes in human corneal endothelium following UVA/riboflavin CXL.

Key Words: Keratoconus - Corneal Endothelium - Specular microscopy-Cross-linking-Riboflavin.

\section{Introduction}

KERATOCONUS is a progressive disorder in which the cornea assumes a conical shape secondary to stromal thinning and protrusion. Both eyes

Correspondence to: Dr. Negm E. Helal, The Department of Ophthalmology, Faculty of Medicine, Ain Shams University are affected at least on topographical imaging, in almost all cases. The hallmark of keratoconus is central or paracentral stromal thinning accompanied by apical protrusion and irregular astigmatism. The disease tends to progress during the adolescent years and into the mid-20s and $30 \mathrm{~s}$, although progression can occur at any time.

The etiology of keratoconus is still largely unknown, although many biochemical and pathological changes at the structural and cellular level of the corneal abnormalities have been suggested.

Patients with keratoconus often complain of decrease in visual acuity which can be mild or severe depending on the degree of corneal tissue affection. Keratoconus can be classified according to the severity of the clinical and topographic signs into mild, moderate and advanced. The clinical manifestations of keratoconus include steepening of the cornea, especially inferiorly, thinning of the corneal apex, corneal scarring, Vogt's striae and Fleischer's ring. In advanced keratoconus, two findings are associated with keratoconus diagnosis; Munson's sign and corneal hydrops

Early in the disorder the astigmatism can be corrected by glasses. With the progression of the protrusion, the astigmatism needs hard contact lenses or even keratoplasty in advanced cases.

\section{Patients and Methods}

This study was a prospective, non-randomised controlled interventional case series. Patients from age 18 to 40 years old diagnosed with progressive keratoconus at Research Institute of Ophthalmology (RIO) Hospitals, were enrolled in the study between October 2016 and April 2017. The diagnosis of progressive keratoconus was based on pentacam 
progression parameters which included at least one of the following (during 1 month follow-up):

- Change of K-max by $\geq 1 \mathrm{D}$.

- Thinning of the cornea by $>30$ m a

- Increase of spherical equivalent (SE) by $\geq 1 \mathrm{D}$

Patients included in the study had: Progressive $\mathrm{KC}$, no history of any ocular surgery, no signs of corneal scarring, avoided the use of contact lens for 1 month before and 6 month after the treatment and had almost 400 central corneal thickness (CCT).

We excluded any patient with history of herpitic keratitis or had history of ocular refractive surgery.

All patients were instructed about the technique and possible complications of the procedure. Patient informed consent was obtained from all participants. Ethics approval was obtained from Resaerch institute of ophthalmology.

A complete ophthalmic history and an opthalmological examination were done for each patient which comprised of:

- Uncorrected visual acuity (UCVA) using snellen chart.

- Best corrected visual acuity (BCVA).

- Anterior segment detailed Slit Lamp examination (SL-450).

- Intraocular preasure.

\section{Specular microscopy:}

Specular microscopy was done for all patients before and after cross linking procedure to evaluate corneal endothelium.

\section{Surgical procedure:}

All patients were treated with UVA/riboflavin CXL under sterile conditions in the operating room. First we scrub periocular skin with $10 \%$ povidoneiodine (Betadine, Mondy pharma) and then we put the opsite and speculum to expose the central corneal area well and then benoxinate hydrochloride $0.4 \%$ (Benox, Alcon) eye drops as topical anaesthetic (used twice: one before starting the procedure and once before UVA exposure).

A micro sponge soaked with ethyl alcohol $20 \%$ was applied onto central part of the cornea for 15 seconds. Then by using a forceps, an $8.0 \mathrm{~mm}$ diameter of central corneal epithelium was removed. The isoosmolar $0.1 \%$ riboflavin solution (Mediocross $\mathrm{M}$, Germany) was instilled every $5 \mathrm{~min}$ for $30 \mathrm{~min}$.
Then UVA irradiation was applied for $30 \mathrm{~min}$ utes at an $8 \mathrm{~mm}$ treatment zone by using UVA system device (OPTO XLinkTM). The parameters of the device were set to: (T) Time 30 minutes and other parameters were automatically set including the Irradiance range (I) and Power of UVA (P). The $0.1 \%$ riboflavin solution was applied every 5 min during the UVA irradiation time. At the end of the procedure, soft bandage contact lens was placed.

\section{Statistical analysis:}

Data were collected, revised, coded and entered to the Statistical Package for Social Science (IBM SPSS) version 20 . The quantitative data were presented as mean, standard deviations and ranges when their distribution found parametric while qualitative data were presented as number and percentages.

The comparison between two paired groups with quantitative data and parametric distribution was done by using Paired $t$-test.

The confidence interval was set to $95 \%$ and the margin of error accepted was set to 5\%. So, the $p$ value was considered significant as the following: $-p>0.05$ : Non significant.

$-p<0.05$ : Significant.

$-p<0.01$ : Highly significant.

\section{Results}

Our study done on Fourty eyes of 40 patients, $22(55.0 \%)$ males, 18 (45.0\%) females. $16(40.0 \%)$ left side, $24(60.0 \%)$ right side. The mean patient age was $27.55 \pm 5.42$ years, range (18-40). All patients completed one month follow-up after treatment.

The mean value of ECD in cross-linked eyes was $2639.68 \pm 218.56$ preoperative, and 2617 . $15 \pm 180.34$ one month postoperative. There was non significant difference between the two mean values ( $p$ 0.497).

Regarding CCT, The mean CCT in cross linked eyes preoperatively was $(466.15 \pm 42.98)$, and the mean value at 1 month post operatively was (457.38 \pm 46.17$)$ with no significant change between the two mean values ( $p$ 0.190).

The mean coefficient of variation (cv\%) value in crosslinked eyes preoperatively was $(29.43 \pm 5.35)$ and 1 month postoperative was $(30.03 \pm 6.01)$ with no significant difference between two values ( $p$ $0.385)$ 
The mean value of hexagonal cells $\%$ in cross linked eyes preoperative was $(65.95 \pm 8.07)$ and at 1 month post operative was $(67.23 \pm 9.11)$ with no significant changes between two mean values ( $p$ $0.475)$.

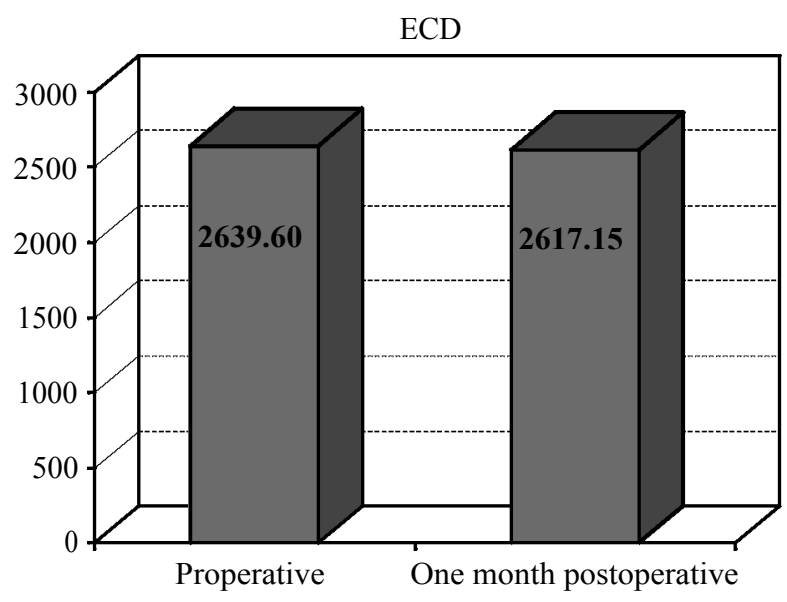

Fig. (1): Showing endothelial cell density before and one month after cross linking.

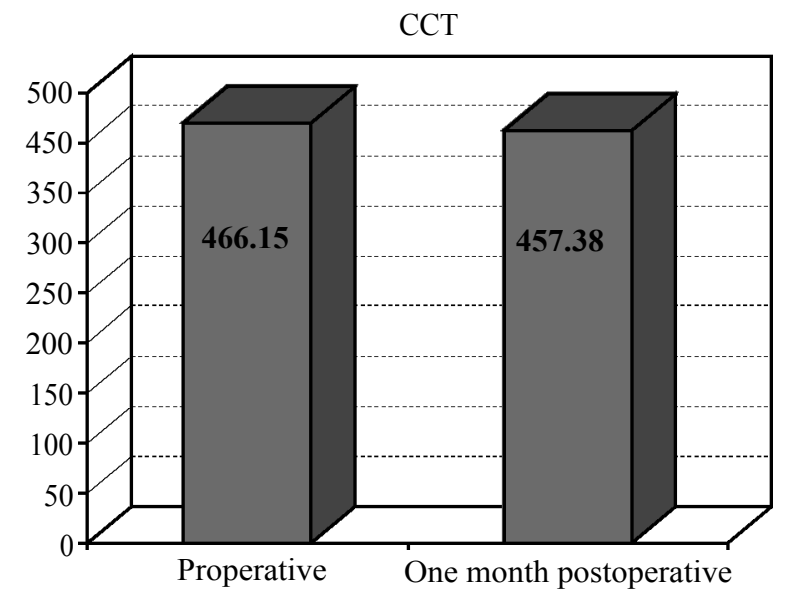

Fig. (2): Showing central corneal thickness before and one month after cross linking.

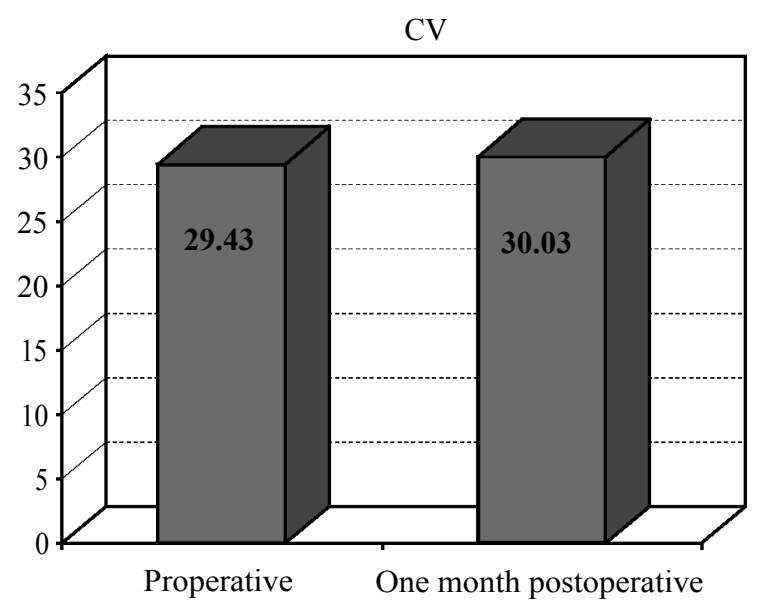

Fig. (3): Statistical analysis of CV\%.

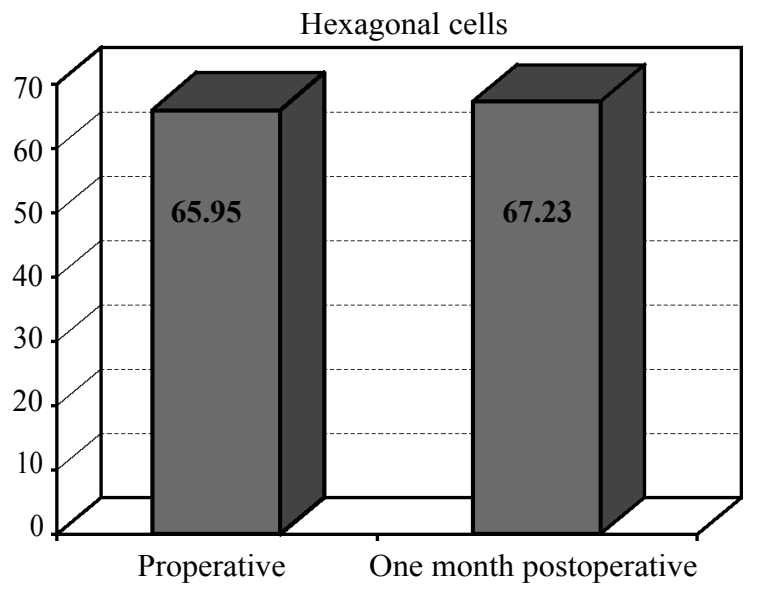

Fig. (4): Statistical analysis of hexagonal cells.

\section{Discussion}

In our study we included patients with progressive keratoconus. Progression was determined topographically as increase in the cone apex keratometry Kmax by $0.75 \mathrm{D}$ ) and with increasing the SE of the patient by $0.75 \mathrm{D}$ over the last 6 months prior to the procedure as reported by many investigators [1]. All of the patients had a CCT almost 400

Our study showed that there were statistically non significant changes in corneal endothelial counts (include CCT, ECD, CV\%, Hexagonal cells $\%)$ after cross linking procedure in keratoconic patients.

Similar to our results, Arora et al., [2] worked on 30 eyes and followed-up them during one year and his study resulted in non statistically significant difference in endothelial cell counts after cross linking procedure, Group A at 1 year $(2888.60 \pm$ $\left.168 \mathrm{c} / \mathrm{mm}^{2}\right)$ and Group B at 1 year $(2880.60 \pm 162 \mathrm{c} /$ $\mathrm{mm}^{2}$ ).

Similarly, Asri et al., [3] worked on 64 eyes and follow-up them during 1 year, his results show no significant change in endothelial cell density ${ }_{2}(\mathrm{ECD})$ after cross linking procedure $+220 \mathrm{c} / \mathrm{mm}$ at 12 months ( $p .07)$.

Also Capoross et al., [4] in 36 months follo-up of 152 tested eyes, his study show no significant changes occur ECD preoperative $\left(2451 \mathrm{c} / \mathrm{mm}^{2} \pm\right.$ $130.444)$ and postoperative ECD range (2092$3016 \mathrm{c} / \mathrm{mm}$ ) And also Central corneal thickness $(\mathrm{CCT})(+10 / \mathrm{m})=0.4092)$ at 1 year.

Similarly, Kymionis et al., [5] during 1 year follow-up of 55 tested eyes, his results show that 
no change in central corneal thickness after cross linking procedure ( $p$ 0.154).

Also, Magli et al., [6] tested 23 eyes and followup them for 1 year, his study agree with our study and show no change in central corneal thickness after cross linking procedure in keratoconic patients CCT preoperative $(487.2 \pm 15.1 \mathrm{~m})$,postoperative $(492 \pm 22.1 \mathrm{~m}),(p 0.5)$.

Also, Hassan et al., [7] show the mean $\pm \mathrm{SD}$ of postoperative percent of hexagonal cells (Pleomorphism) was $54.14 \pm 6$ and postoperative percent was $54.55 \pm(p$-value $=0.517)$ indicate no significant change.

In contrary, Richichi et al., [8] worked on 28 eyes and follow-up them during 1 year and his result show significant decrease in central corneal thickness after cross linking procedure preoperative $(444 \pm 28 \mathrm{~m})$, postoperative $432.88 \pm 28 \mathrm{~m}) \mathbf{m}$

Also, Arora et al., [2] worked on 30 eyes (2 Groups) and follow-up them for 1 year and his result show significant decrease in central corneal thickness in Group A (from $447.53 \pm 33.35$ to $383.07 \pm 58.53 \mathrm{~m}$ ) 12 months, In Group B (from $414.5 \pm 16.89$ to $346.05 \pm 23.89 \mathrm{~m}) \mathrm{moth}$ $(p=0.001)$

Similarly, Asri et al., [3] worked on 46 eyes and follow them during 1year; his results show significant decrease in central corneal thickness preoperative $442 \pm 49$ ostoperative 12 month (409 $\pm 67 \mathrm{~m}) \mathbf{c}$

Also, Magli et al., [6] his study on 23 eyes during 12 months follow-up disagree with our study show significant decrease in endothelial cell density after CXL (preoperative ECD $3212 \pm 331$ $01 \mathrm{c} / \mathrm{mm}^{2}$, postoperative $\left(3188 \pm 147.1 \mathrm{c} / \mathrm{mm}^{2}\right)(p .07)$
And, Hassan et al., [7] show there was a significant reduction in ECD after CXL ( $p$-value $=0.004)$. The least decrease in cell density was found in patients with corneal thickness less than $450 \mathbf{m}$, while these patients had the thinnest cornea. The mean \pm SD op the co-efficient of variation of endothelial cell size (CV) before and after CXL were $32.72 \pm 10.14$ and $40.21 \pm 9.70$, respectively ( $p$-value $=0.0021)$.

\section{References}

1- O'BRART D.P., CHAN E., SAMARAS K., et al.: A randomised, prospective study to investigate the efficacy of riboflavin/ultraviolet A $(370 \mathrm{~nm})$ corneal collagen crosslinkage to halt the progression of keratoconus. Br. J. Ophthalmol., 95: 1519-1524, 2011.

2- ARORA R., JAIN P., et al.: Comparative analysis of refractive and topographic changes in early and advanced keratoconic eyes undergoing corneal collagen crosslinkin g. Cornea., 2013.

3- ASRI D., TOUBOUL D., et al.: Corneal collagen crosslinking in progressive keratoconus: Multicenter results from the French National Reference Center for Keratoconus. J. Cataract. Refract. Surg., 37 (12): 2137-2143, 2011.

4- CAPOROSSI A., MAZZOTTA C., et al.: RiboflavinUVA-induced corneal collagen cross-linking in pediatric patients. Cornea., 31 (3): 227-231, 2012.

5- KYMIONIS G.D., PORTALIOU D.M., et al.: Corneal collagen cross-linking with riboflavin and ultraviolet-A irradiation in patients with thin corneas. Am. J. Ophthalmol., 153: 24-8, 2012.

6- MAGLI A., FORTE R., et al.: Epithelium-off corneal collagen cross -linking versus transepithelial cross-linking for pediatric keratoconus. Cornea., 32 (5): 597-601, 2013.

7- HASSAN R., SEYED M., GHOREISHI, et al.: Comparison of the findings of endothelial specular microscopy before and after corneal cross-linking. Advanced Biomedical Research, 2015.

8- RECHICHI M., DAYA S., et al.: Epithelial-disruption collagen crosslinking for keratoconus: One-year results. J. Cataract. Refract. Surg., 39 (8): 1171-1178, 2013. 


\section{تقييم التغيرات بالخلايا الطلائية الداخلية للقرثية

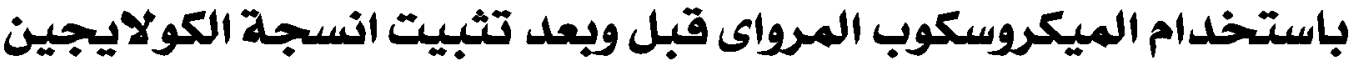 العلاج القرنية المخروبل ودوطية تئية}

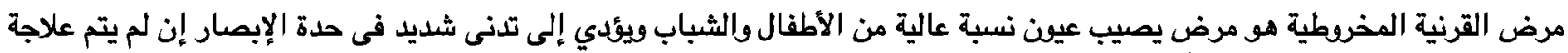

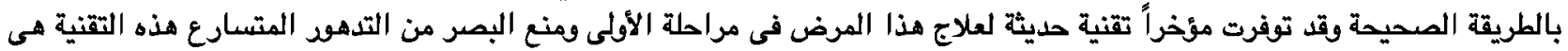

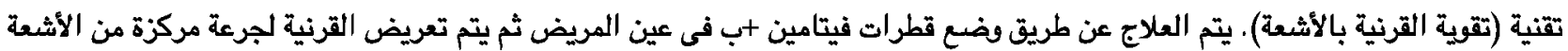

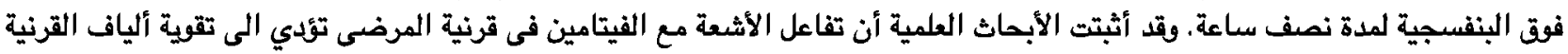

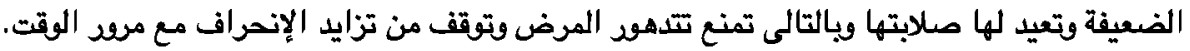

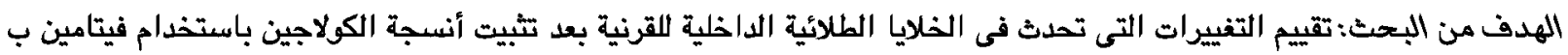

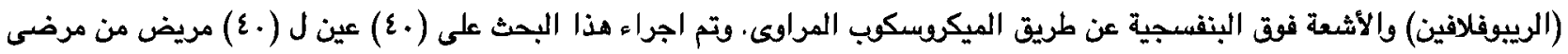
القرنية المخروطية. وقد تبين عدم وجود تغيرات فى الخلايا الطلائيه الداخليه للقرنيه بعد شهر متابعه بعد التبييت بالريبوفلافيلافين 